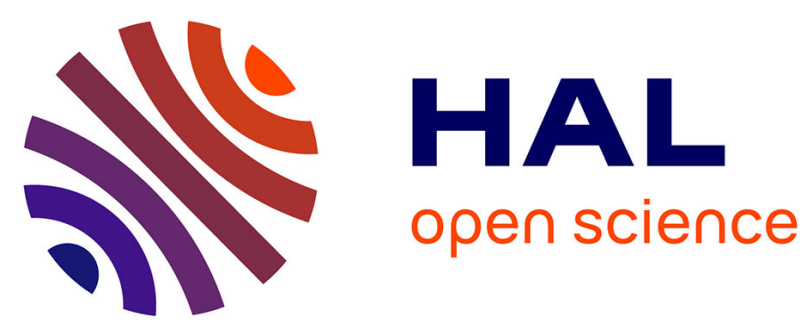

\title{
Use of hydrocarbons sludge as a substrate for the production of biosurfactants by Pseudomonas aeruginosa ATCC 27853
}

Imane Kezrane, Bassirou Mahamadou Harouna, Mabrouk Hamadache, Othmane Benkortbi, Abdeltif Amrane

\section{To cite this version:}

Imane Kezrane, Bassirou Mahamadou Harouna, Mabrouk Hamadache, Othmane Benkortbi, Abdeltif Amrane. Use of hydrocarbons sludge as a substrate for the production of biosurfactants by Pseudomonas aeruginosa ATCC 27853. Environmental Monitoring and Assessment, 2020, 192 (5), pp.287. 10.1007/s10661-020-08269-3 . hal-02563402

HAL Id: hal-02563402

https://hal-univ-rennes1.archives-ouvertes.fr/hal-02563402

Submitted on 27 May 2020

HAL is a multi-disciplinary open access archive for the deposit and dissemination of scientific research documents, whether they are published or not. The documents may come from teaching and research institutions in France or abroad, or from public or private research centers.
L'archive ouverte pluridisciplinaire HAL, est destinée au dépôt et à la diffusion de documents scientifiques de niveau recherche, publiés ou non, émanant des établissements d'enseignement et de recherche français ou étrangers, des laboratoires publics ou privés. 


\title{
Use of hydrocarbons sludge as a substrate for the production of biosurfactants by
} Pseudomonas aeruginosa ATCC 27853

\author{
Imane Kezrane ${ }^{1}$, Bassirou Mahamadou Harouna ${ }^{1,2}$, Mabrouk Hamadache ${ }^{1}$, \\ Othmane Benkortbi ${ }^{1 *}$, Abdeltif Amrane ${ }^{3}$, \\ ${ }^{1}$ Biomaterials and Transport Phenomena Laboratory (LBMPT), Department of Engineering \\ Process and Environment, Faculty of Technology, University of Medea-Algeria, \\ ${ }^{2}$ Industrial Process Engineering and Control Analysis Laboratory (GEPICA), Ecole des \\ Hautes Etudes en Génie de l'Eau, des Procédés Industriels et de l'Environnement \\ (HEGEPRINE), Niamey - Niger. \\ ${ }^{3}$ Univ-Rennes, Ecole Nationale Supérieure de Chimie de Rennes, CNRS, ISCR - UMR6226, \\ F-35000 Rennes, France \\ Email:imanekez@yahoo.com; bassymaham@gmail.com; mhamdeche@yahoo.fr; \\ benkortbi_oth@yahoo.fr; abdeltif.amrane@univ-rennesl.fr
}

\begin{abstract}
The purpose of this study was to elucidate the capacity of a Pseudomonas aeruginosa strain to metabolize hydrocarbons sludge in the production of biosurfactants to fight against environmental threats. The performance of the treatment consisted in monitoring the inductive metabolism of the strain during $48 \mathrm{~h}$ at a temperature of $37^{\circ} \mathrm{C}$. The results showed that a removal efficiency of $96.8 \%$ and an emulsification index of $71.8 \%$ were obtained corresponding to a phosphate buffer concentration of $30 \mathrm{mmol} / \mathrm{L}$. The main role of the biosurfactants produced was to emulsify the medium and to absorb the oils contained in the hydrocarbons sludge. This allowed to stabilize hydrocarbons oils and favored the inductive metabolism of P. aeruginosa. Furthermore, Physico-chemical and Fourier transform infrared spectroscopy (FTIR) analysis showed that the produced biosurfactants were of rhamnolipid type. They showed promising surfactant properties, such as a strong reduction in the surface tension of water from $72 \mathrm{mN} / \mathrm{m}$ to $40.52 \mathrm{mN} / \mathrm{m}$, a high reactivity in the culture medium at $\mathrm{pH} 7$, a high osmotolerance up to 150 $\mathrm{g} / \mathrm{L}$ of salt, and a critical micellar concentration of $21 \mathrm{mg} / \mathrm{L}$. Indeed, the observed inductive metabolism constitutes an opportunity of treatment of various hydrocarbons contained in crude oil and spilled in the ecosystem to prevent pollution and damage.
\end{abstract}


Keywords: Hydrocarbons sludge; Pollution; Refinery; Recycling; Enzymatic induction Growth; Biosurfactants.

\section{Introduction}

Hydrocarbons sludge is an effluent provided from the crude oil refining industry resulting from various processes along the crude oil processing lines. They constitute a serious threat to the environment and need to be treated to avoid harming human health and the sustainability of the ecosystems. (Linda et al., 2016).

The study conducted by Pan et al., 2015 evaluates several essential state-of-the-art waste-toenergy (WTE) technologies including combustion, gasification and anaerobic digestion. Since strategies under appropriate policies were essential for the implementation of the WTE supply chain, a critical review on the challenging barriers and overcome strategies was performed. Several successful case studies around the world were illustrated based on their respective energy, environmental and economic benefits of the WTE supply chain for the district energy supply (DES) system. Qomarudin et al., 2010, described the problem of oil waste management as a consideration of the environmental impact of the oils contained in the waste. The production of hydrocarbons sludge is massive since oil production has increased in all producing countries as a result of its involvement in their economies, (Bhattacharyya et al., 2003); for instance, it can reach up to 2000 tons/day in Indonesia (Tse , 2003). This raise in petroleum production has increased the threat to the environment and has reached the sub-soil, (Qomarudin et al., 2010). The amount of hydrocarbons sludge continues to increase and its severity on the environment becomes worrying due to the density, and the viscosity of the oils contained. Generally, higher refining capacity is associated with a higher amount of oil sludge production (Wang et al., 2012; Guangji et al., 2013). The oil contained in the sludge crosses the earth's layer and slowly reaches the subsoil, which poses a direct risk of contamination of the subsoil and shallow groundwater.

In addition, the light hydrocarbons evaporated in the sludge are mixed with atmospheric dust, which causes air pollution during the harmattan season. This evaporation phenomenon provokes serious respiratory problems and eventually human disease and environmental damage.

Irreversible ecological disasters can be realized during releases or voluntary dumping. They present a significant toxicological risk even at low concentrations, in particular by their mutagenic and carcinogenic properties (Cravo-Laureau et Duran 2016). 
In order to preserve the environment and eliminate these pollutants, it is necessary to develop reliable and effective methods of pollution control. The diagnosis of the treatment techniques used has shown major imperfections that can cause harm to human health, the ecosystem, and the environment. In this aim, Marin et al., 2005, studied the bioremediation of a refinery sludge containing hydrocarbons using agricultural techniques, to assess its ability to reduce the total content of hydrocarbons added to the soil with the sludge in a semi-arid climate and also to evaluates its effect on the microbial activity of the soil concerned.

Despite the multiple uses of physicochemical processes in the restoration of soil polluted by petroleum products, bioremediation remains the most effective, best controlled and least costly solution. Its principle is based on the complete mineralization of petroleum products which do not generate any toxic by-product. (Azubuike et al., 2016; Rajesh et al., 2017).

The addition of surfactants is a promising approach to increase the biodegradation of hydrocarbons. Nevertheless, these molecules of chemical origin present a risk to the environment due to their toxicity and their non-biodegradability (Geetha et al., 2018; Banat et al., 2000). Recently, several authors were interested in the production of biosurfactants due to the advantages presented by these biomolecules compared to their chemical counterparts, such as biodegradability, low toxicity, efficacy under extreme conditions $(\mathrm{pH}$, temperature and salinity) ( Makkar et al., 2011). Furthermore, as result of their emulsification and solubilization capacity, they have many potential applications covering a wide variety of fields such as medicine, the petroleum industry and the bioremediation of sites contaminated by hydrocarbons (Santos et al. ., 2017). Biosurfactants produced from Pseudomonas aeruginosa are constituted by the rhamnose fraction and the fatty fraction resulting from the growth on the hydrocarbon substrate, they are specific to a given carbon substrate for the growth of the producing strain. In their study, Montagnolli et al., 2019 compared the effects of biosurfactants on the biodegradation of biodiesel and vegetable oils by two conceptually divergent methodologies. They found that biosurfactants caused an increase in oil absorption, increasing biodegradation performance. Also, they found that the biodiesel substrate stood out with the highest biodegradation rates. These results indicated that a rapid metabolic shift from the parent compound initially favored biodiesels in the uptake of organic carbon for a set of specialized microbial inoculum. The data has been successfully combined with mathematical models and statistical tools to describe and predict the actual environmental behavior of biodiesel and vegetable oils. The models confirmed and predicted the effectiveness of biodegradation with biosurfactants and allowed to estimate the time needed to satisfactorily remove contaminants. 
The enzymes involved in the conversion of hydrocarbons in P. aeruginosa are of two types, namely rhamnotransferase I and II with self-inductive capacity. However, in the literature, no author was interested in the efficiency of the inductive metabolism of $P$. aeruginosa in removing the oils contained in the residual sludge of the petroleum refining industries. The bacterial genus Pseudomonas is characterized by a multitude type of biosurfactants and synthesizing enzymes by induction in a medium in which phosphate and nitrogen are limiting. The enzymatic induction phenomenon of $P$. aeruginosa is at the origin of the synthesis of several rhamnolipids (Hanna et al., 2011; Ellen et al., 2014). Also, the metabolic process of $P$. aeruginosa constitutes a great opportunity for the discharge sites by the presence of biosurfactants which enrich the environment with biodegradable organic substances (Abhijit et al., 2014; Tanja et al.,2017).

The challenge of this study dealing with the treatment of hydrocarbons sludge is to highlight the importance of the inductive metabolism of $P$. aeruginosa in the elimination of hydrocarbons oils in sludge. For this purpose, the physicochemical behavior of the biosurfactants produced, allowing the extraction of the oils contained in the sludge by wetting, solubilization, and emulsification was examined. In addition, the conditions for the inductive growth of the strain leading to an efficient elimination and evacuation of sludge without risk of ecosystem degradation were investigated.

\section{Materials and methods}

The strain used in this work was $P$. aeruginosa ATCC 27853. It was kindly provided by the hospital of Medea (Algeria). The hydrocarbons sludge was furnished by the Niger-SORAZ industry. It was packaged in powder form after several treatments to destroy all traces of microorganisms. The culture medium was formulated according to the medium proposed by Milena et al., 2012. It was conditioned using an oven, and then wet heated in an autoclave. Biomass growth (OD at $600 \mathrm{~nm}$ ) and hydrocarbon consumption by COD (transmittance at 420 $\mathrm{nm}$ ) monitoring were performed using a spectrophotometric method.

\section{Culture medium formulation}

To ensure the microbiological quality of the hydrocarbons sludge, double sterilization was undertaken. The first step consisted of humidifying the hydrocarbons sludge to reactivate all the microorganisms contained. The hydrocarbons sludge were then placed in an oven for one 
hour at $180^{\circ} \mathrm{C}$ before being cooled to $70^{\circ} \mathrm{C}$. In addition, $1 \mathrm{~g}$ of this suspension was dissolved in $100 \mathrm{~mL}$ of distilled water. This solution was then tested on a solid agar medium for a period of 48 to $72 \mathrm{~h}$ at $37^{\circ} \mathrm{C}$. The second step consisted of sterilization with moist heat at $121^{\circ} \mathrm{C}$ for 15 minutes followed by the same test to evaluate the sterility (Pacheco et al., 2010).

The culture medium formulated for the production of glycolipids biosurfactantwas constituted by the following mixture: $\mathrm{NaCl}(1 \mathrm{~g} / \mathrm{L}) ; \mathrm{KNO}_{3}(4 \mathrm{~g} / \mathrm{L}) ; \mathrm{MgSO}_{4} \times 3 \mathrm{H}_{2} \mathrm{O}(0.2 \mathrm{~g} / \mathrm{L}) ; \mathrm{CaCl}_{2} \mathrm{x} 2 \mathrm{H}_{2} \mathrm{O}$ $(0.05 \mathrm{~g} / \mathrm{L}) ; \mathrm{FeCl}_{3} \times 7 \mathrm{H}_{2} \mathrm{O}(0.01 \mathrm{~g} / \mathrm{L})$; yeast extract $(6 \mathrm{~g} / \mathrm{L})$; as well as $\mathrm{KH}_{2} \mathrm{PO}_{4}$ monobasic phosphate buffer $(4 \mathrm{~g} / \mathrm{L}) .1 \mathrm{~mL} / \mathrm{L}$ of the following trace elements solution was added to the culture medium: $\mathrm{ZnSO}_{4}(50 \mathrm{mg}) ; \mathrm{MnSO}_{4}(23 \mathrm{mg}) ; \mathrm{FeSO}_{4} \times 5 \mathrm{H}_{2} \mathrm{O}(10 \mathrm{mg}) ; \mathrm{CuSO}_{4}(10 \mathrm{mg})$; $\mathrm{CaCl}_{2} \mathrm{X} 6 \mathrm{H}_{2} \mathrm{O}$ (36 mg); $\mathrm{H}_{3} \mathrm{BO}_{3}(12 \mathrm{mg}) ; \mathrm{KI}(15 \mathrm{mg}$ ) and EDTA (80 mg). (Milena et al., 2012). The hydrocarbons sludge powder 3\% (w/v) was added as a source of carbon and energy to the medium (Linda et al., 2016). The solution was dissolved and magnetically stirred for 5 min for homogenization. The medium was adjusted to a $\mathrm{pH}=6.0 \pm 0.01$ by the addition of sodium hydroxide solution $(1 \mathrm{~N})$ or hydrochloric acid $(1 \mathrm{~N})$. It was then sterilized for 15 minutes at $121^{\circ} \mathrm{C}$ in an autoclave. After sterilization, the medium was cooled with tap water and the $\mathrm{pH}$ was then adjusted to $\mathrm{pH}=7.0 \pm 0.01$ before inoculation, (Patil et al., 2014).

\section{Culture conditions}

The culture was performed in batch mode at $37^{\circ} \mathrm{C}$ for $48 \mathrm{~h}$ with an agitation speed $\mathrm{W}=250$ $\mathrm{rpm}$ at $\mathrm{pH}=7.00 \pm 0.01$. Germination was carried out in a sterilized solid selective medium (cetrimide agar) for 24 hours containing as carbon source a mixture of n-heptane and cetane to prevent a long latency phase. The microbial cells were then seeded for $48 \mathrm{~h}$ of culture with a regular sampling of $10 \mathrm{~mL}$ every $2 \mathrm{~h}$ on average for kinetic monitoring (Saimmai et al., 2012).

\section{Kinetic Monitoring}

The kinetic study focused on biomass growth through the measurement of the optical density at $600 \mathrm{~nm}$, which was examined versus the evolution of nitrogen, the consumption of hydrocarbons sludge and the productivity of biosurfactants. Samples of $10 \mathrm{~mL}$ were collected and centrifuged at $\mathrm{W}=6000 \mathrm{rpm}$ for 10,15 and $20 \mathrm{~min}$ with the removal of the residual solid mass ; this latter was diluted in $10 \mathrm{ml}$ of water and measured at $600 \mathrm{~nm}$. Then, $2 \mathrm{~mL}$ of cellfree medium was taken for the preparation of the emulsifying index. The emulsion samples were left for $24 \mathrm{~h}$. The emulsifying index $\mathrm{EI}_{24} \%$ was given by the ratio between the height of 
the emulsified layer on that of the whole column (Kumara et al., 2006; Aparna et al., 2011). The rest of the cell-free medium was precipitated after 24, 48, 72 and $96 \mathrm{~h}$, with absolute ethanol $(1: 3 \mathrm{v} / \mathrm{v})$, then centrifuged and maintained for $24 \mathrm{~h}$ at $4^{\circ} \mathrm{C}$ (Prabakaran et al., 2015). Biosurfactants were recovered and dried in a vacuum desiccator. The precipitated medium was measured by the COD-spectroscopic method at $420 \mathrm{~nm}$. Samples of $2 \mathrm{~mL}$ were then taken, diluted and digested in a digester. The monitoring of the biomass growth was performed by optical density (OD) at $600 \mathrm{~nm}$ using a UV/VIS spectrophotometer (Senthil et Jayalakshmi, 2013). The nitrogen concentration in the culture medium during the treatment was determined by the iron oxidation method in acidic medium, followed by a spectrophotometric determination of ferrous ion at $510 \mathrm{~nm}$.

\section{Effect of the phosphate buffer}

The effect of buffer was performed owing to its significant impact on culture; it stimulates growth, the associated production of biosurfactants and stabilizes the $\mathrm{pH}$ of the medium (Graziela et al., 2010). Experiments were spread on an experimental scale according to the lower and upper limits of buffer concentration and productivity. It allows to find a maximum production of biosurfactants and to determine the stimulating effect of the buffer on the growth of the strain. This assessment was done according to three key areas, namely low stimulation, optimal stimulation and repressive stimulation (Bassirou et al 2019).

\section{Characterization of the Biosurfactants}

The detection of biosurfactants in the medium during the culture was based on the emulsification index and the method of Cooper and Goldenberg (1987). In addition, a test was carried out to demonstrate the rhamnose fraction of the biosurfactants produced based on the determination of hydrocarbon groups of the biosurfactants using the method of Dubois et al (Dubois et al., 1956). A volume $\mathrm{V}=0.5 \mathrm{~mL}$ of cell-free medium was collected and mixed with $0.5 \mathrm{~mL}$ of phenol solution $(5 \%)$ and $2.5 \mathrm{~mL}$ of sulfuric acid. The mixture was set for 15 minutes and then the absorbance was read at $490 \mathrm{~nm}$.

FTIR Characterization of crude biosurfactants 
The infrared method was used to analyze the crude biosurfactants and to identify its various groups, characteristic of biomolecules (Prabakaran et al., 2015). The characterization method consisted of assaying $\mathrm{KBr}$ pellets of $0.23 \mathrm{~mm}$ containing a small amount of crude biosurfactants. The analysis was then carried out in a wavelength range from $400 \mathrm{~cm}^{-1}$ to 4000 $\mathrm{cm}^{-1}$ with a resolution of $2 \mathrm{~cm}^{-1}$. The unit was controlled by software (IR/FP Solutions) which regulated the humidity and the ambient air (correction of atmospheric carbon dioxide).

Physicochemical characterization of biosurfactants.

\section{Surface tension and CMC}

Equilibrium surface tension $(\gamma)$ was measured at a temperature of $25^{\circ} \mathrm{C}$ with a Krüss $\mathrm{K} 9$ digital tensiometer (Krüss, Helsinki, Finland) by the ring method of the aqueous solution at different concentrations of crude biosurfactant (Habib et al., 2013). The instrument was calibrated against ultrapure water $(\gamma=72 \mathrm{mN} / \mathrm{m}$ ) to ensure accuracy over the entire range of surface tension. The ring was rinsed with ethanol than with water to avoid any particles or dust which may contaminate the latter (Milena et al., 2012). For the calibration of the instrument, the surface tension of distilled water was measured before each series of experiments. All assays were performed in triplicate along with distilled water as a control.

\section{Effect of the salinity}

The effect of salinity on aqueous solutions of crude biosurfactant was studied by adding $\mathrm{NaCl}$ in the range of 25 to $250 \mathrm{~g} / \mathrm{L}$ with a step of $25 \mathrm{~g} / \mathrm{L}$. After addition, the samples were placed in the dark for 20 minutes. The objective was to assess the reactivity of the biosurfactant facing extreme chemical conditions. Thus, the monitoring was carried out by measurements of the surface tension after the addition of $\mathrm{NaCl}$ (Rajesh et al., 2014).

\section{Effect of the $p H$}

The stability of the biosurfactant versus $\mathrm{pH}$ variations was examined using a solution of $0.6 \mathrm{~g} / \mathrm{L}$ of crude biosurfactant. The $\mathrm{pH}$ of the samples was adjusted within a range of 2 to 12 with a step of 1 for biosurfactant concentrations in the range of 1 to $600 \mathrm{mg} / \mathrm{L}$ (Habib et al., 2013). The 
surface tension of the solutions was measured after adjusting the $\mathrm{pH}$ and after 30 minutes of contact time. This allowed to determine the optimal $\mathrm{pH}$ linked to the reactivity of the biosurfactant tested and also to evaluate the activity of the bioproducts regarding $\mathrm{pH}$ variations of the medium (Govindammal et Parthasarathi, 2013).

\section{Displacement and oil solubilization}

The oil displacement test is a method of determining the surface activity of the biosurfactant by measuring clear zone diameter. The method of displacement of the oil by solubilization was used to measure the stretching area diameter of the immiscible oil. The solubilization and displacement were provoked by the addition of an aqueous solution of crude biosurfactant at the oil-water interface (Rath et al., 2016).

The following procedure was considered to study the oil displacement, namely the expansion of the diameter of the oil droplet on a surface of distilled water: a Petri dish was filled with 50 $\mathrm{mL}$ of distilled water, a volume of $20 \mu \mathrm{L}$ of oil was deposited on the surface of water, and then $15 \mu \mathrm{L}$ of a solution of the crude biosurfactant at a concentration of $1 \mathrm{~g} / \mathrm{L}$ was filled on the oil surface (Hamid et al., 2012).

Moreover, to investigate the solubility of the oil in an aqueous solution of crude biosurfactant, a Petri dish was filled with $25 \mathrm{~mL}$ of a $1 \mathrm{~g} / \mathrm{L}$ biosurfactant solution ; then, $15 \mu \mathrm{L}$ of oil were removed and deposited on the surface of the aqueous solution of crude biosurfactant. In both cases, the value of the diameter of the oil displacement was expressed in $\mathrm{cm}$.

\section{Results and discussion}

The treatment efficiency characterizes the bioconversion and the efficiency of the treatment of hydrocarbon sludge to avoid damage to the environment and the ecosystem. It responds to the objective assigned to treatment, and therefore to the development of decontamination technologies in environments polluted by hydrocarbons. This allows to have a completely biodegradable and stable product, $\mathrm{ES} 5 \mathrm{D}=96.17 \%$ for an emulsification index $\mathrm{EI}_{24}=71.80 \%$, useful for various industries.

The results obtained include the regeneration of all the genetic material, the production of primary metabolites (enzymes, structural proteins, intra, and extracellular signaling systems, nucleic acids ...), since Pseudomonas aeruginosa synthesizes a complex called quorum whose maturity is essential to the growth and the production of secondary metabolites in fermentative 
medium. Facing this consideration, the hydrocarbon and nitrogen substrates abruptly decreased between 0 and $3 \mathrm{~h}$, leading to a treatment yield of $36.5 \%$ after $3 \mathrm{~h}$. Also, a part of the substrate was used for the production of biosurfactants stimulated by the presence of hydrocarbon substrates.

The characteristic of the biosurfactants produced should highlight the importance of its biomolecules in the treatment of hydrocarbons sludge by their actions of wetting, solubilization, emulsification and extraction of the contained oils. The presence of biosurfactants in the medium promotes the contact between the microbial cells of Pseudomonas aeruginosa and the source of carbon and energy, namely the hydrocarbons contained in the sludge, to achieve optimal growth.

\section{Determination of the phosphate buffer concentration}

The determination of the phosphate buffer content, both as a growth stimulant and for $\mathrm{pH}$ stabilization was envisaged. The results regarding the evaluation of the importance of the phosphate buffer are summarized in Table 1, showing an optimum for $30 \mathrm{mmol} / \mathrm{L}$.

\section{Table 1. Comparative results of phosphate buffer values. Threshold and optimal}

$$
\text { concentrations }\left(\mathrm{pH}=7, \mathrm{~T}=37^{\circ} \mathrm{C}, \mathrm{W}=250 \mathrm{rpm}\right) \text {. }
$$

In light of the results obtained and based on the tests carried out, the lowest critical value of productivity was $10 \mathrm{mmol} / \mathrm{L}$. It is important to note that the initial conductivity measurements are subject to the effect of the measured temperature and the volume of sodium hydroxide or hydrochloric acid used for $\mathrm{pH}$ adjustment after medium sterilization and cooling, (Cha et al., 2008; Priya et Usharani 2009). Nutrients assimilation allowed to decrease the conductivity of the medium to an extreme level, having a significant impact on the beginning of the growth and biosurfactant production. In addition, when the buffer concentration is low in the medium, the conductivity of nitrate ions dominates the overall conductivity, owing to the high conductivity of this anion.

Biosurfactants productivity showed a steady evolution until 40 hours, while there was an increase of almost $10 \%$ at $48 \mathrm{~h}\left(\mathrm{EI}_{24}=57.2 \%\right)$ (Fig. 1); this result is in agreement with previous reports (Senthil et Jayalakshmi, 2013). This account for the inefficiency of the buffer, since the conductivity at the beginning of biosurfactants production $(\mathrm{G}=11.20 \mathrm{mS} / \mathrm{cm}$ after $3 \mathrm{~h}$ of 
culture) had not reached the threshold value of productivity observed with $30 \mathrm{mmol} / \mathrm{L}$ after 48 $\mathrm{h}, \mathrm{G}=15.10 \mathrm{mS} / \mathrm{cm}$. This conductivity value was however observed after $48 \mathrm{~h}$ of culture, (Ould boudia, 2013). The increased production of biosurfactants obtained at $40 \mathrm{~h}$ can be related to a deficiency in nutrients and especially hydrocarbons substrate. Indeed, such nutrients limitation induced an increase in biosurfactants production to solubilize the remaining hydrocarbons substrate $(20.12 \mathrm{mg} / \mathrm{L}$ for $10 \mathrm{mmol} / \mathrm{L}$ of phosphate buffer).

It can also be noted that the consumption of nitrogen (nitrate) with respect to hydrocarbons was $0.20 \mathrm{~g} / \mathrm{g}$ of carbon source. Nitrates consumption for $10 \mathrm{mmol} / \mathrm{L}$ buffer was nearly identical to the value observed for $30 \mathrm{mmol} / \mathrm{L}$. The stimulating effect of the buffer was therefore observable in these conditions since this latter did not induce a significant difference regarding the lowering of the conductivity of the medium allowing maximal growth of the strain. Therefore, as shown through the emulsification index (Table 1), an increase in the production of biosurfactants was observed from $40 \mathrm{~h}$ of culture due to nutrients starvation (Wei et al., 2005; Whang et al., 2008). Productivity was significantly lower both in terms of biomass and product level, confirming the importance of the buffer for the growth of the strain.

Fig. 1. Evolution of the emulsification index versus time $\left(\mathrm{pH}=7, \mathrm{~T}=37^{\circ} \mathrm{C}, \mathrm{W}=250 \mathrm{rpm}\right.$,

$$
\left.\mathrm{KH}_{2} \mathrm{PO}_{4}=10 \mathrm{mmol} / \mathrm{L}, \mathrm{p} \leq 0.05\right) \text {. }
$$

Whereas, the value of $50 \mathrm{mmol} / \mathrm{L}$ buffer showed to be critical in terms of repression of the strain by the salinity of the medium (Ilori et al., 2005), the emulsification index at this level showed a maximum at $5 \mathrm{~h}$ before declining abruptly up to $48 \mathrm{~h}$. Medium conductivity did not decrease to a threshold limit allowing growth and biosurfactant production, owing to the lack of salt tolerance of the used strain; conductivity remained almost constant throughout culture (Table 1). From this, it can be assumed that nitrate respiration most likely occurred throughout the culture.

As shown in Fig 2a and b, the best emulsification was obtained between $3 \mathrm{~h}$ and $7 \mathrm{~h}$. Indeed, to produce biosurfactants without variations of the other medium components, the buffer concentration must satisfy the optimal physiological needs of the strain to allow an adequate response to the stimulus. Therefore, the concentration of $50 \mathrm{mmol} / \mathrm{L}$ exceeded the optimal needs of Pseudomonas aeruginosa ATCC 27853 in the considered medium and hence caused a repressive stimulation of the strain (Gorna et al., 2011; Al-Saleh et Akbar 2015).

In agreement with the work of Anna et Partchasarathi (2014), owing to the excess of salinity due to the phosphate buffer, cell lysis was observed since the considered Pseudomonas strain 
was not osmotolerant. As shown in Fig $2 \mathrm{a}$ and $\mathrm{b}$, this effect can be compared to that of $\mathrm{NaCl}$ (Rikalović et al., 2012; Anna et Partchasarathi, 2014).

The N/C ratio showed that $0.67 \mathrm{~g}$ of nitrate was needed to consume $1 \mathrm{~g}$ of carbon, namely three times the normal respiration observed for the value of $30 \mathrm{mmol} / \mathrm{L}$. This shows that the environment was not optimal for high biosurfactants production, since the components of the environment were not well balanced (Dos-Santos et al., 2010; Senthil et Jayalakshmi 2013). In addition, an approximate lethality and inhibition of the emulsification index were estimated to be $27.3 \%$ and $19.9 \%$, respectively. Lethality and inhibition were deduced from the ratios of the emulsification index values at 24 and $48 \mathrm{~h}$ for the former and 7 and $22 \mathrm{~h}$ for the latter (Bassirou et al., 2019), according to the following equations:

$$
\begin{gathered}
\text { Lethality }=\frac{E I_{24} \text { from } 24 h \text { to } 48 h}{E I_{24 \text { max } \text { obtained }}} \times 100 \%-100 \% \\
\text { Inhibition }=\frac{E I_{24 \text { from } 7 \text { hto } 48 h} \times 100 \%-100 \%}{E I_{24} \text { max obtained }}
\end{gathered}
$$

Fig. 2. Biomass (a) and Emulsification index versus time (b) $\left(\mathrm{pH}=7, \mathrm{~T}=37^{\circ} \mathrm{C}, \mathrm{W}=250 \mathrm{rpm}\right.$,

Culture conditions

$$
\left.\mathrm{KH}_{2} \mathrm{PO}_{4}=50 \mathrm{mmol} / \mathrm{L}, \mathrm{p} \leq 0.05\right) \text {. }
$$

Fig 3 a, b, c and d shows growth in two-steps, illustrating enzymatic induction growth namely diauxic phenomena. Regarding the results represented in Fig. 3, the first growth phase, until 20 $\mathrm{h}$, corresponded to the consumption of the most readily treatment hydrocarbons contained in the sludge and then the less biodegradable hydrocarbons contained was assimilated until $48 \mathrm{~h}$ of culture (Bassirou et al., 2017).

The treatment efficiency can be estimated to be $\theta=96.8 \%$ with a final hydrocarbons source concentration $\mathrm{C}=250.1 \mathrm{mg} / \mathrm{L}$ and a nitrogen to carbon ratio $\mathrm{N} / \mathrm{C}=20.85 \%$; consequently, the biomass on substrate yield was $\mathrm{Y}_{\mathrm{X} / \mathrm{S}}=52.7 \%$ and the product on substrate yield was $\mathrm{Y}_{\mathrm{P} / \mathrm{S}}=$ $20.3 \%$ over $48 \mathrm{~h}$ of culture. The quantitative productivity showed two maxima (Fig $3 \mathrm{~d}$ ), $\mathrm{P}_{1}=$ 
$64.1 \mathrm{mg}$ at $7 \mathrm{~h}$ and $\mathrm{P}_{2}=75.6 \mathrm{mg}$ at $28 \mathrm{~h}$ corresponding to each exponential phase of growth (Fig. 3a).

Based on the related literature, the comparison of the emulsification index obtained in 30 $\mathrm{mmol} / \mathrm{L}$ buffer and the concentration of biosurfactants produced $(\mathrm{C}=1560 \mathrm{mg} / \mathrm{L})$ suggests that the diauxic growth in the present work occurred on a substrate approaching a lighter substrate as kerosene for the first phase and diesel for the second phase (Wei et Chu , 2002). Furthermore, the results of Fig. 3 demonstrated the presence of two hydrocarbons sources in the medium and growth by enzymatic induction or diauxic growth, which characterizes the metabolic pathway of the strain. The two peaks reflected the presence of two rhamnolipids, because of the specificity of biosurfactants to the carbon substrate and the productivity associated with growth.

Fig. 3. Evolution of Growth (a); hydrocarbons substrate consumption (b); nitrogen uptake (c) and biosurfactants product $(\mathrm{d})$ versus time $\left(\mathrm{pH}=7, \mathrm{~T}=37^{\circ} \mathrm{C}, \mathrm{W}=250 \mathrm{rpm}, \mathrm{KH}_{2} \mathrm{PO}_{4}=30\right.$ $\mathrm{mmol} / \mathrm{L}, \mathrm{p} \leq 0.05)$.

Following the Cooper and Goldenberg method, the emulsification kinetics showed the existence of two peaks, corroborating the growth of the strain and the evolution of substrates assimilation. As shown in Fig. 4, the values of the emulsification indexes $\mathrm{EI}_{24}$ found are of $46.70 \%$ at $7 \mathrm{~h}(1)$ and $71.80 \%$ at $46 \mathrm{~h}$ (2). These two emulsification peaks correspond perfectly to inductive or diauxic growth

Fig.4. Emulsification index versus time $\left(\mathrm{pH}=7, \mathrm{~T}=37^{\circ} \mathrm{C}, \mathrm{W}=250 \mathrm{rpm}, \mathrm{KH}_{2} \mathrm{PO}_{4}=30 \mathrm{mmol} / \mathrm{L}\right.$, $\mathrm{p} \leq 0.05)$.

The stability of the emulsion over five days allowed to test the biosurfactants according to the time and the environmental factors. According to Figure 5, the emulsions remained stable after five days. They showed ES5D stability of $81.63 \%$ for the first growth phase with an $\mathrm{EI}_{24}$ of $46.70 \%$ and ES5D stability of $96.17 \%$ for the second growth phase with an $\mathrm{EI}_{24}$ of $71.80 \%$. This stability of the formulated foaming is important for the treatment on-site of the sludge discharges without risk of degradation of the ecosystem due to the capacity of the biosurfactants to extract the oils contained in the sludge (Yan et al., 2012). The treatment yield was intrinsically dependent on the stability of the formulated foaming.

Fig. 5. Stability of the emulsions against the time after five days 
Characterization of the biosurfactants

402

403

Biosurfactants were characterized by highlighting their presence in the cell-free medium. For this purpose, emulsions were prepared under Cooper and Goldenberg conditions. Consistency and stability can be related to the emulsification index after $24 \mathrm{~h}$. Indeed, no disintegration of the emulsion was observed during the five days of monitoring at ambient temperature. The quality of the foam proves the importance of the molecular weight of the biosurfactants produced. The formation of flocs was very fast because of their high molecular weight. The rhamnose test, at $490 \mathrm{~nm}$ absorbance, was positive, showing their glycolipids structure and rhamnolipid type.

\section{Infrared Characterization of the crude biosurfactants}

The obtained spectrum showed two regions with two peaks of maximum absorbance characteristics of the functional groups. The first of high intensity included two amplitudes. The first at $3420 \mathrm{~cm}^{-1}\left(\mathrm{OH}^{-}\right.$band alcohol, typical of polysaccharides $)$and the second at $3277.17 \mathrm{~cm}^{-}$ ${ }^{1}\left(\mathrm{OH}^{-}\right.$band characteristic of carboxylic acid). This band constitutes a stretching vibration of the O-H groups, carboxylic acid dimmers, with large absorption of the band O-H between 3300 and $2500 \mathrm{~cm}^{-1}$; while the second region had a peak of high intensity of narrowband which absorbed at $1105 \mathrm{~cm}^{-1}$. The characteristic band of carboxylic acids was easily distinguishable from that of alcohol by its lower and extended absorbance, covering the $\mathrm{C}-\mathrm{H}$ bands, in contrast to that of alcohol between $3420 \mathrm{~cm}^{-1}$ and $1105 \mathrm{~cm}^{-1}$. Besides these bands, the spectrum showed two bands of $2862.46 \mathrm{~cm}^{-1}$ and $2926.11 \mathrm{~cm}^{-1}\left(\mathrm{C}-\mathrm{H}\right.$ bands characteristic of a $\mathrm{CH}_{2}-\mathrm{CH}_{3}$ hydrocarbon chain).

Other bands can also be observed, at $1647.26 \mathrm{~cm}^{-1}$ (characteristics of $\mathrm{C}=\mathrm{O}$ ester groups) and at $1454.38 \mathrm{~cm}^{-1}$ (characteristics of $\mathrm{C}-\mathrm{H}$, asymmetric of $\mathrm{CH}_{3}$ ) (Amani et al., 2010; Pereira et al., 2013). Thus, the extended C-O band, which absorbs from 1105.25 to $1384.94 \mathrm{~cm}^{-1}$, characterized the presence of a bond between the carbon atoms and the hydroxyl groups of the chemical structure of rhamnose. According to Govindammal et Partchasarathi (2013); Anna et Partchasarathi (2014), the maximum absorption observed at $3466.24 \mathrm{~cm}^{-1}$ and $3424.60 \mathrm{~cm}^{-1}$ can be attributed to $\mathrm{OH}^{-}$groups and those at $881.50 \mathrm{~cm}^{-1}$ and $698.25 \mathrm{~cm}^{-1}$ are characteristic of $\mathrm{CH}_{2}$ 
groups ; all characteristics of the rhamnose cycle, showing that the obtained infrared spectrum was consistent with the glycolipids structure and the rhamnolipid type of the obtained biosurfactants (Fig. 6).

Fig. 6. Spectral IR characterization of biosurfactants produced by Pseudomonas aeruginosa ATTC 27853.

Glycolipids are composed of carbohydrates and long-chain aliphatic acids or hydroxyl aliphatic acids. An example of the most widely studied glycolipids is rhamnolipids produced by $P$. aeruginosa strains. Although there are several types of rhamnolipid species, all of them possess similar chemical structures. In general, the two major types of rhamnolipid species are 1rhamnosyl-3-hydroxydecanoyl-3-hydroxydecanoate or mono-rhamnolipid ( $\left.\mathrm{Rha}-\mathrm{C}_{10}-\mathrm{C}_{10}\right)$ and 1-rhamnosyl 1-rhamnosyl-3-hydroxydecanoyl-3-hydroxydecanoate or di-rhamnolipid (RhaRha- $\left.\mathrm{C}_{10}-\mathrm{C}_{10}\right)$ (Prabakaran et al., 2015).

In comparison to the results obtained by Prabakaran et al., (2015) by FTIR analysis of biosurfactants products and Habib et al. (2013) related to the physicochemical characterization of mono-rhamnolipid, the biosurfactants product in the present study according to the FTIR result analysis are di and mono-rhamnolipids. According to the enzymatic induction phenomenon (diauxic growth) displayed in the fig. 3, the difference in the composition of rhamnolipid species might be due to the age of the culture, the strain of $P$. aeruginosa, substrate composition and the specific culture conditions (Habib et al., 2013). Although the bacterium produced predominantly a di-rhamnolipid, it also produced a mono-rhamnolipid in minor proportion.

Physicochemical characterization of the biosurfactants

\section{Surface tension and CMC}

The CMC is an index used to evaluate the surface-active activity that is the minimum biosurfactants concentration needed to achieve the lowest values of surface tension, from which the formation of micellar aggregates begins (Juliana et Crispin, 2013). Fig.7 exhibits the variation of the surface tension according to the concentration of biosurfactants in aqueous solutions. Indeed, the crude biosurfactants showed a lowering capacity of the surface tension of water from $\gamma=71.80 \mathrm{mN} / \mathrm{m}$ at $25^{\circ} \mathrm{C}$ to $\gamma=40.52 \mathrm{mN} / \mathrm{m}$ with a crude biosurfactants 
concentration $\mathrm{C}=600 \mathrm{mg} / \mathrm{L}$. The critical micellar concentration of the biosurfactant was $\mathrm{CMC}$ $=(21.0 \pm 0.1) \mathrm{mg} / \mathrm{L}$ for a series of samples between $\mathrm{C}=[0-150] \mathrm{mg} / \mathrm{L}$ as shown in Fig 7 . It is significantly above sodium dodecyl sulfate (SDS), a synthetic surfactant commonly used in many industrial sectors, which has a CMC of $21.0 \mathrm{mg} / \mathrm{L}$ in the same conditions test (Juliana et Crispin, 2013).

Fig. 7. Evolution of the surface tension versus the biosurfactants concentrationconcentration $\left(\mathrm{pH}=7, \mathrm{~T}=37^{\circ} \mathrm{C}, \mathrm{W}=250 \mathrm{rpm}, \mathrm{KH}_{2} \mathrm{PO}_{4}=30 \mathrm{mmol} / \mathrm{L}, \mathrm{p} \leq 0.05\right)$.

\section{Effect of the salinity}

The results of the stability effect related to the action of $\mathrm{NaCl}$ on the biosurfactants showed a strong reactivity in the medium below the CMC in terms of lowering the surface tension, even exceeding the behavior observed in the absence of salt. It was found that the addition of $\mathrm{NaCl}$ from 25 to $100 \mathrm{~g} / \mathrm{L}$, for biosurfactant concentrations ranging from 0 to $20 \mathrm{mg} / \mathrm{L}$ increased the efficiency of the biosurfactants to reduce the surface tension of the medium owing to the competition induced between the electrolytes.

However, beyond the CMC a slight increase in the surface tension was observed despite a very good reactivity of the crude biosurfactants. This increase should be most likely related not only to a competition effect, but even more to medium saturation by the electrolytes. The saturation concentration of $\mathrm{NaCl}$ was $\mathrm{C}=150 \mathrm{~g} / \mathrm{L}$ for a concentration $\mathrm{C}=37 \mathrm{mg} / \mathrm{L}$ of biosurfactants. The maximum reduction of the surface tension was $\gamma=32.36 \mathrm{mN} / \mathrm{m}$. Several authors described similar behavior for biosurfactants produced by other microorganisms, P. putida, Bacillus subtilis, P. aeruginosa, B. cereus and Rhodococcus erythropolis (Morikawa et al., 2000; Xia et al., 2011).

\section{Effect of the $p H$}

The stability's tests related to the $\mathrm{pH}$ indicated the ability of biosurfactants to react facing an increase of the ionic strength above and below the CMC, in terms of lowering the surface tension after $\mathrm{pH}$ adjustment. The results showed that $\mathrm{pH}=7$ was optimal for biosurfactant reactivity allowing a sufficient lowering of the surface tension (Fig.8).

The $\mathrm{pH}$ is an important factor, it can limit or enhance the effect of biosurfactants in the medium. The effect of the $\mathrm{pH}$ is characterized by a modification of the surface charges of the 
biosurfactants contained in the crude extract depending on the critical micellar concentration. It is at the origin of the solubilizing, wetting, foaming and emulsifying capacity of biosurfactants during culture. In an acidic medium, the surface tension decreased gradually until a value $\mathrm{C}=18.75 \mathrm{mg} / \mathrm{L}$. The electrical competitiveness of the biosurfactants resulted from negative charges which allow the stability of molecules, particularly di-rhamnolipids, in agreement with the related literature (Amani et al., 2010; Xia et al., 2011)

From $\mathrm{pH} 4$, the acidity of the medium caused a considerable decrease in surface tension by modifying the specific CMC due to mono-rhamnolipids. The CMC previously determined depended on the variation of the $\mathrm{pH}$ of the medium and decreased with acidic $\mathrm{pH}$. In an alkaline medium, the decrease in surface tension was due to the presence of highly reactive monorhamnolipids in this $\mathrm{pH}$ range. This reactivity can be related to their negative repulsive charges which stabilize the emulsification of the medium in terms of the heterogeneous nature of the fatty acids of the mono-rhamnolipids produced by P. aeruginosa (Özdemir et al., 2004 : Zhong et al., 2008).

However, for $\mathrm{pH}$ values greater than 7, most of the mono-rhamnolipid molecules are negatively charged, while they are neutral at $\mathrm{pH}$ 4. Thus, the determined CMC was characteristic of a mixture of mono and di-rhamnolipids produced simultaneously by the strain depending on the nature of the carbon source (Habib et al., 2013). For low ionic strengths $(\mathrm{NaCl}=0-50 \mathrm{mM})$, the neutral mono-rhamnolipid had a CMC value less than the ionized form. This difference could be explained by the presence of electrostatic repulsions between the neutral and negatively charged mono-rhamnolipid molecules, which made their association in the micellar aggregates more difficult, compared to the neutral molecules present at $\mathrm{pH} 4.0$.

Similar results were found using P. aeruginosa, B. subtilis, R. erthropolis, P. putida and B. cereus (Morikawa et al., 2000; Chen et al., 2010; Ikhwani et al., 2017).

Fig. 8. Evolution of the surface tension of the crude biosurfactant versus $\mathrm{pH}$ (a) and $\mathrm{NaCl}$ amount (b)

$$
\left(\mathrm{T}=37^{\circ} \mathrm{C}, \mathrm{W}=250 \mathrm{rpm}, \mathrm{KH}_{2} \mathrm{PO}_{4}=30 \mathrm{mmol} / \mathrm{L}, \mathrm{p} \leq 0.05\right) \text {. }
$$

\section{Displacement and solubilization of oil}

The purpose of the displacement and the solubilization of oil is to highlight the ability of the biosurfactants to solubilize and expand the oil droplet deposited on a hydrophilic surface. A high capacity of the biosurfactants to solubilize and to move the oil after the contact of $20 \mu \mathrm{L}$ 
of a $1 \mathrm{~g} / \mathrm{L}$ biosurfactants solution with $15 \mu \mathrm{L}$ of oil deposited on $50 \mathrm{~mL}$ of distilled water was shown. This confirmed the high capacity of the biosurfactants in the solubilization of immiscible liquids, by lowering the interfacial tension between oil and water and by an enlargement of the oil diameter from 0 to $2.5 \mathrm{~cm}$. This displacement occurs due to the decrease of the oil viscosity.

Hamid et al. (2012) and Rath et al. (2016) described qualitatively the activity of the biosurfactants by crossing the barrier of the oil droplet deposited on the surface of the water by the solution of biosurfactant which gradually expands the oil diameter. It is in agreement with the observed action of the biosurfactants produced by Pseudomonas aeruginosa ATCC 27853 applied to the oil droplet deposited on the surface of the water.

Furthermore, the displacement of the oil on $25 \mathrm{~mL}$ of biosurfactants at a concentration of $1 \mathrm{~g} / \mathrm{L}$ reached up to $5-8 \mathrm{~cm}$; it is in agreement with the related literature (Rath et al., 2016). Indeed, the oil was dissolved in the solution of biosurfactants by expanding its diameter. This result highlighted the solubilizing capacity of the produced biosurfactants and can be the subject of a more widespread application for the environmental safeguarding and protecting against the pollution of hydrocarbons sludge of refinery.

\section{Conclusion}

The results obtained showed the performance and the efficiency of the treatment of hydrocarbons sludge of Pseudomonas aeruginosa strain using the combined effect of biosurfactants and inductive metabolism. This observed phenomenon showed the ability of Pseudomonas aeruginosa to grow on complex hydrocarbons. The presence of biosurfactants had a positive effect on the mobility of hydrophobic components of soil, facilitating the leaching of hydrocarbons contained in the sludge. The mechanism of wetting, solubilization, emulsification and extraction by biosurfactants of Pseudomonas aeruginosa is an useful way to remove hydrocarbons oils. Ultimately, the application of the crude biosurfactants in the solubilization and the displacement of oil confirmed the promising properties of the rhamnolipids produced and hence, to prevent pollution and damage, it constitutes an opportunity of treatment of various hydrocarbons contained in crude oil and spilled into the ecosystem.

\section{Acknowledgements}


566 The authors gratefully acknowledge the team of biomaterials and transport phenomena

567 Laboratory (LBMPT) and the University of Medea.

\section{Conflict of interest}

569

570 The authors declare that there is no conflict of interests.

571

572 Author Disclosure Statement

573

574 No competing financial interests exist.

575

576 Abbreviation

577

578 C: concentration $(\mathrm{mg} / \mathrm{L})$;

579 CMC: critical micellar concentration $(\mathrm{mg} / \mathrm{L})$;

580 COD: chemical oxygen demand

581 DES: district energy supply;

$582 \quad \mathrm{EI}_{24}$ : emulsification index (\%);

583 FTIR: Fourier Transformer Infrared;

584 G: conductivity $(\mathrm{mS} / \mathrm{cm})$;

585 OD: optical density;

586 Rp: speed of the biosurfactants production (mg/h.L);

587 V: volume $(\mathrm{mL})$;

588 W: speed of rotation ( $\mathrm{rpm})$;

589 WTE: waste-to-energy;

$590 \quad \mathrm{X}$ : normalized biomass $(\mathrm{g})$;

$591 Y_{\mathrm{X} / \mathrm{S}}$ : yield of biomass/substrate (\%);

592 Y Y/S: yield of product/substrate (\%)

$593 \gamma$ : surface tension $(\mathrm{mN} / \mathrm{m})$;

594

\section{$595 \quad$ References}

596 Abhijit, S. R., Reshita, B., Maina, B., Anil, K. S., Hari, P. D. B., Neelima, S., Manab, D., Nipu, 597 D., \& Tarun, C. B. (2014). Bioremediation potential of native hydrocarbon degrading bacterial 
598

599

600

601

602

603

604

605

606

607

608

609

610

611

612

613

614

615

616

617

618

619

620

621

622

623

624

strains in crude oil contaminated soil under microcosm study. International Biodeterioration and Biodegradation, 94, $79-89$.

Al-Saleh, I., \& Akbar A. (2015). Occurrence of Pseudomonas aeruginosa in Kuwait soil. Chemosphere.120, $100-107$.

Amani, H., Sarrafzadeh, M. H., Haghighi, M., \& Mehrnia, M. R. (2010). Comparative study of biosurfactant producing bacteria in MEOR applications. Journal of Petroleum Science and Engineering. 75, $209-214$.

Anna, J. P., \& Partchasarathi, R. (2014). Production and Characterization of Biosurfactant from Pseudomonas aeruginosa PBSC1 isolated from mangrove ecosystem. African Journal of Biotechnology.13, 3394-3401.

Aparna, A., Srinikethan, G., \& Hegde, S. (2011). Effect of Addition of Biosurfactant Produced by Pseudomonas sps on Biodegradation of Crude Oil. $2^{\text {nd }}$ International Conference on Environmental Science and Technology IPCBEE vol. 6 Singapore, IACSIT Press.

Azubuike, C. C., Chikere, C. B., \& Okpokwasili, G. C. (2016). Bioremediation techniquesclassification based on site of application: principles, advantages, limitations and prospects. World Journal of Microbiology and Biotechnology, 32 (11), 180.

Banat, I. M., Makkar, R. S., \& Cameotra, S. S. (2000). Potential commercial applications of microbial surfactants. Applied Microbiology and Biotechnology, 53:495-508.

Bassirou, M.H., Benkortbi, O., Hamadache, M., \& Hanini, S. (2017). Optimization of diauxienne growth of Pseudomonas aeruginosa in bioremediation of soils polluted by Hydrocarbons. $3^{\text {rd }}$ International Symposium on Materials and Sustainable Development, Boumerdes - Algeria, November 07 \& 08, 2017 sciences conf. org: cimdd 2017:161255, 456

Bassirou, M.H., Bachir, B.I., Benkortbi, O., \& Amrane, A. (2019). A new alternative of hospital hygiene enhanced facing Pseudomonas aeruginosa drug resistance. Impact of hypertonic saline solutions on the behavior of Pseudomonas aeruginosa. ACS Omega 2019, 4, 475-482.

Bhattacharyya, J. K., \& Shekdar, A.V. (2003). Treatment and disposal of refinery sludges: Indian scenario. Waste Management and Research. 21, 249-261. 
Cha, M. N., Lee, M., Kim, M., \& Lee, S. (2008). Heterologous production of Pseudomonas aeruginosa EMS1 biosurfactant in Pseudomonas putida. Bioresource Technology. 99, 21922199.

Chen, M. L., Penfold, J., Thomas, R. K., Smyth, T. J. P., Perfumo, A., Marchant, R., Banat, I. M., Stevenson, P., Parry, A., Tucker, I., \& Grillo, I. (2010). Solution self-assembly andadsorption at the air-water interface of the mono-rhamnose and di-rhamnoserhamnolipids and their mixtures. Langmuir 26, 18281-18292.

Cooper D. G., \& Goldenberg B. G. (1987). Surface-active agents from two Bacillus species. Applied and Environmental Microbiology. 53, 224-229.

Cravo-Laureau, C., \& Duran, R. (2014). Marine coastal sediments microbial hydrocarbon degradation processes: Contribution of experimental ecology in the omics'era. Frontiers in microbiology. 5. 39. 10.3389/fmicb.2014.00039.

Dos-Santos, S. C., Fernandez, J. C., Rossi-Alva, J. C., \& Roque, M. (2010). Evaluation of substrates from renewable-resources in biosurfactant production by Pseudomonas strains. African J. Biotechnol.9, 5704 - 5711.

Dubois, M., Gills, K. A., Hamilton, J. K., Rebers, P. A., \& Smith, F. (1956). Colorimetric Method for Determination of Sugars and Related Substances.Anal.Chem.28, 350 - 356.

Souza, E. C., Vessoni-Penna, T. C., \& de Souza Oliveira, R. P. (2014). Biosurfactant-enhanced hydrocarbon bioremediation: An overview. International biodeterioration \& biodegradation, $89,88-94$.

Geetha, S. J., Banat, I. M., \& Joshi, S. J. (2018). Biosurfactants: Production and potential applications in microbial enhanced oil recovery (MEOR) Biocatal Agric Biotechnol, 14 pp. 2332 ,

Gorna, H., Ławniczak, L., Kowiak, A.Z., \& Kaczorek, E. (2011). Differences and dynamic changes in the cell surface properties of three Pseudomonas aeruginosa strains isolated from petroleum-polluted soil as a response to various carbon sources and the external addition of rhamnolipids. Bioresource Technology. 102, 3028-3033. 
652 Govindammal, M., \& Parthasarathi, R. (2013). Production and Characterization of 653 Biosurfactant Using Renewable Substrates by Pseudomonas fluorescence isolated from Mangrove Ecosystem. Journal of Applied Chemistry. 2, 55 - 62.

655

656

657

658

659

660

661

662

663

664

665

666

667

668

669

670

671

672

673

674

675

676

677

678

Graziela, J.P., Elisa, M.P.C., Edelvio-de-Barros, G., \& Nei, P.J. (2010).Biosurfactant production by Rhodococcuserythropolis and its application to oil Removal. Brazilian Journal of Microbiology. 41, $685-693$.

Guangji, H., Jianbing, L., \& Guangming, Z. (2013). Recent Development in the Treatment of Oily Sludgefrom Petroleum Industry - A Review. Journal of Hazardous Materials. 261, 470 490.

Habib, A., Kambiz, A.N., Mir, M.H., Hossein, Shahbani, Z., Ali, A.M-M., Massoud, A., José, A.T., \& Antonio, O. (2013). Physicochemical characterization of a monorhamnolipid secreted by Pseudomonas aeruginosa MA01 in aqueous media.An experimental and molecular dynamics study. Colloids and Surfaces B: Biointerfaces. 101, 256- 265.

Hamid, K., Habib, A., Sam, A., \& Kambiz, N. (2012). Frothability and surface behavior of a rhamnolipid biosurfactant produced by Pseudomonas aeruginosa MA01. Biochemical Engineering Journal. 60, 127- 134.

Hanna, G., Łukasz, Ł., Agnieszka, Z-G-K., \& Ewa, K. (2011). Differences and dynamic changes in the cell surface properties of three Pseudomonas aeruginosa strains isolated from petroleum-polluted soil as a response to various carbon sources and the external addition of rhamnolipids. Bioresource Technology. 102, 3028-3033.

Ikhwani, A. Z. N., Nurlaila, H. S., Ferdinand, F. D. K., Fachria, R., Hasan, A. E. Z, Yani, M., Setyawati, I., \& Suryani (2017). Preliminary study: optimization of pH and salinity for biosurfactant production from Pseudomonas aeruginosa in diesel fuel and crude oil medium. IOP Conference Series: Earth and Environmental Science. 58012056

Ilori, M.O., Amobi, C.J., \& Odocha, A.C. (2005). Factors affecting biosurfactant production by oil degrading Aeromonas spp isolated from a tropical environment.Chemosphere. 61, 985 992. 
679

680

681

682

683

684

685

686

687

688

689

690

691

692

693

694

695

696

697

698

699

700

701

702

703

704

705

Juliana, G-de-O., \& Crispin, H.G-C. (2013). Properties of a Biosurfactant Produced by Bacillus pumilus Using Vinasse and Waste Frying Oil as Alternative Carbon Sources. Brazilian Archives of Biology and Technology. 56, 155-160.

Kłosowska-Chomiczewska, I.E., Mędrzycka1, K., \& Karpenko, E. (2012). Biosurfactants Biodegradability, Toxicity, Efficiency In Comparison With Synthetic Surfactants.Lviv Academy of Sciences, Lviv, Ukraine and Gdansk University of Technology, Gdansk, Poland. pp.8.

Kumara, M., Leon V., De-Sisto, M.A., Ilzins, O.A., Galindo-Castro, I., \& Fuenmayor, S.L. (2006). Polycyclic Aromatic Hydrocarbon Degradation by Biosurfactant-Producing Pseudomonas sp. IR1. Z Naturforsch C. 61, $203-212$.

Linda U. Ob., Harrison, I.A., \& Rasheed, A.A. (2016). Isolation and characterisation of crude oil sludge degrading bacteria. Springer Plus. 5, 1932 - 1946.

Makkar, R.S., Cameotra S.S., \& Banat I.M. (2011). Advances in utilization of renewable substrates for biosurfactant production. AMB Express. 1, 1-5.

Marin, J.A., Hernandez, T., \& Garcia, C. (2005). Bioremediation of oil refinery sludge by land farming in semiarid conditions: Influence on soil microbial activity. Environmental Research, $98,185-195$.

Milena, G.R., Gordana, G-C., Miroslav M.V., \& Ivanka, K. (2012). Production and characterization of rhamnolipids from Pseudomonas aeruginosa san-ai. Journal of the Serbian Chemical Society.77, 27-42.

Montagnolli, R. N., Cruz, J. M., Moraes, J. R., Mendes, C. R., Dilarri, G., Lopes, P. R. M., \& Bidoia, E. D. (2019). Technical approaches to evaluate the surfactant-enhanced biodegradation of biodiesel and vegetable oils. Environmental Monitoring and Assessment, 191(9), 565.

Morikawa, M., Hirata, Y., \& Imanaka, T. (2000). A study on the structure-function relationship of lipopeptide biosurfactant. Biochemica et Biophysica Acta.1488, 211 - 218.

Ould boudia. A. (2013). Bioremediation of crude oils / complex mixture of hydrocarbons $(\mathrm{CMH})$ contaminants in seawater by a halotolerant bacterial under aerobic conditions: 
Enterobacter cloacae, Pseudomonas spp. and Escherichia coli. Global Advanced Research Journal of Microbiology. 2, $131-136$.

Özdemir, G., Peker, S., \& Helvaci, S.S. (2004). Effect of pH on the surface and interfacial behavior of rhamnolipids R1 and R2, Colloids and Surface. A Physicochemical and Engineering Aspects 234, 135-143.

Pacheco, G.J., Prioli, C.E.M., Gomes, E.B., \& Junior, N.P. (2010). Biosurfactant production by rhodococcus erythropolis and its application to oil. Brazilian Journal of Microbiology. 41, 685 $-693$.

Pan, S. Y., Du, M. A., Huang, I. T., Liu, I. H., Chang, E. E., \& Chiang, P. C. (2015). Strategies on implementation of waste-to-energy (WTE) supply chain for circular economy system: a review. Journal of Cleaner Production, 108, 409-421.

Patil, S., Pendse, A., \& Aruna, K. (2014). Studies on optimization of biosurfactant production by Pseudomonas aeruginosa F23 isolated from oil contaminated soil sample. International Journal of Current Biotechnology . 2, 20-30.

Pereira, J.F.B., Gudina, E.J., Costa, R., Vitorino, R., Teixeira, J.A., Coutinho, J.A.P., \& Rodrigues, L.R. (2013). Optimization and characterization of biosurfactant production by Bacillus subtilis isolates towards microbial enhanced oil recovery applications. Fuel Journal.111, $259-268$.

Prabakaran, G., Hotib, S.L., Surya, P.R.H., \& Satish, V. (2015). Di-rhamnolipid is a mosquito pupicidal metabolite from Pseudomonas fluorescens (VCRC B426). Acta Tropica. 3558 3566.

Priya, T., \& Usharani, G. (2009). Comparative Study for Biosurfactant Production by Using Bacillus subtilis and Pseudomonas aeruginosa. Botany Research International. 2, 284 - 287.

Qomarudin, H., Edwan, K., Zeily, N., \& Wisjnuprapto. (2010). Application of Biosurfactant Produced by AzotobacterVinelandii AV01 for Enhanced Oil Recovery and Biodegradation of Oil Sludge. International Journal of Civil and Environmental Engineering.10, 6 - 12.

Rabelo-de-Sousa, J., Costa, C.J.A., Lima-de-Almeida, J.G., Rodrigues, S., Loiola, P.O.D., Melo, V. M., \& Barros, G. L. R. (2011). Evaluation of a co-product of biodiesel production as 
carbon source in the production of biosurfactant by $P$. aeruginosa MSIC02. Process Biochemistry. 46, 1831-1839.

Rajesh M., Samundeeswari M., \& Archana B. (2017). Isolation of biosurfactant producing bacteria from garbage soil. Journal of Applied \& Environmental Microbiology. 5:74-8.

Rajesh, K., Sathyanarayana, N.G., \& Suresh, K.G. (2014). Production and Characterization of Biosurfactant by Pseudomonas putida MTCC 2467. Journal of Biological Sciences. 14, 436445.

Rath, K., Singh, A.B., Chandan. S., \& Vatsala, R.S. (2016). Isolation and Characterization of a Biosurfactant Producing Strain Pseudomonas aeruginosa SMVIT 1 from Oil Contaminated Soil. Journal of Scientific and Industrial Research.75, $681-686$.

Rikalović, M.G., Cvijović G.G., Vrvić1 M.M., \& Karadžić I. (2012). Production and characterization of rhamnolipids from Pseudomonas aeruginoa. Journal of the Serbian Chemical Society. 77, 27-42.

Saimmai, A., Rukadee, O., Sobhonand, V., \& Maneerat, S. (2012). Biosurfactant production by Bacillus subtilis TD4 and Pseudomonas aeruginosa SU7 grown on crude glycerol obtained from biodiesel production plant as sole carbon source. Journal of Scientific and Industrial Research. 71, 396-406.

Santos, A., Silva, M., Costa, E., Rufino, R. D., Santos, V. A., Ramos, C. S., \& Porto, A. (2017). Production and characterization of a biosurfactant produced by Streptomyces sp. DPUA 1559 isolated from lichens of the Amazon region. Brazilian Journal of Medical and Biological Research, 51(2), 6657.

Senthil, B.S., \& Jayalakshmi, S. (2013). Glycolipid biosurfactant production using low cost medium from marine bacterium Pseudomonas aeruginosa of Mudasalodai coast. International Journal of Green Chemistry and Bioprocess. 3, 33-37.

Tanja, J., Jelena, A., Srđan, M., Latinka, S-B., Dalibor, S., Jelena, M., Mila, I., Vladimir, B., Gordana, G-C., \& Miroslav, M.V. (2017).Transformation and synthesis of humic substances during bioremediation of petroleum hydrocarbons. International Biodeterioration \& Biodegradation. 122, $47-52$. 
Tse, P.K., (2003). The mineral industries of indonesia and east timor (timor-leste). U.S. geological survey minerals yearbook.

Wang, X., Wang, Q.H., Wang, S.J., Li, F.S., \& Guo, G.L. (2012). Effect of biostimulation on community level physiological profiles of microorganisms in field-scale biopiles composed of aged oil sludge. Bioresource Technology. 111: 308-315.

Wei, Y.H., Choub, C.L., \& Chang, J.S. (2005). Rhamnolipid production by indigenous Pseudomonas aeruginosa J4 originating from petrochemical wastewater. Biochemical Engineering Journal. 27, 146-154.

Wei, Y.H., \& Chu, I.M. (2002). Manganese improves surfactin production by Bacillus subtilis. Biotechnology Letters, 24: $479-482$.

Whang, L.M., Liu, P.W., \& Ma, C.C. (2008). Application of biosurfactant, rhamnolipid and surfactant, for enhanced biodegradation of diesel-contaminated water and soil. Journal of Hazardous Materials. 151, 155 - 163.

Xia, W.J., Dong, H.P., Yu, L., \& Deng, F.Y. (2011). Comparative study of biosurfactant produced by microorganisms isolated from formation water of petroleum reservoir. Colloids and Surfaces A-Physicochemical and Engineering Aspects. 392, 124 - 130.

Yan, P., Lu, M., Yang, Q., Zhang, H.L., Zhang, Z.Z., \& Chen, R. (2012). Oil recovery from refinery oily sludge using a rhamnolipidbiosurfactant-producing by Pseudomonas. Bioresource Technology. 116, 24-28.

Zhong, H., Zeng, G.M., Liu, J.X., Xu, X.M., Yuan, X.Z., Fu, H.Y., Huang, G.H., Liu, Z.F., \& Ding, Y. (2008). Adsorption of monorhamnolipid and dirhamnolipid on two Pseudomonas aeruginosa strains and the effect on cell surface hydrophobicity, Applied Microbiology and Biotechnology. 79, 671-677. 